\title{
Do "Off" ao "On" no Mercado Atacado de Moda: o Potencial de Influenciadores Digitais
}

\section{From Off to On in the Wholesale Fashion Market: the Potential of Digital Influencers}

\author{
Ricardo Limongi \\ Ana Paula Cândida Dias \\ André Luiz Barbosa da Silva \\ Denise Santos de Oliveira \\ Otávio Bandeira de Lamônica Freire
}

Este caso de ensino aborda a implementação do canal online de um shopping atacadista de moda que anteriormente possuía suas estratégias de marketing focadas no offline. A mudança ocorreu devido à queda significativa na taxa de ocupação das lojas entre os anos de 2018 e 2019 geridas pelo shopping. Para evoluir em direção ao ambiente digital os gestores do shopping realizaram uma reestruturação na equipe de marketing que optou, inicialmente, por utilizar a estratégia digital com influenciadores digitais. Dessa forma, o objetivo deste caso é fomentar discussões sobre as dificuldades no processo de escolha de influenciadores digitais e principalmente em relação aos resultados obtidos além das mídias digitais.

Palavras-chave: influenciadores digitais; shopping; marketing digital; moda.

Abstract: This teaching case addresses implementing a wholesale fashion mall's online channel that previously had its non-offline marketing strategies. The mall managed the change due to the drop in the store occupancy rate between 2018 and 2019. The mall managers selected the marketing team that opted to evolve towards the digital environment, a newsletter for using the digital strategy with digital influencers. Thus, this case's objective is to promote the difficulties in choosing digital influencers and especially concerning the results selected in addition to digital media.

Keywords: digital influencers; shopping; digital marketing; fashion.
Recebido em: 17/08/2020

Aprovado em: 16/09/2020

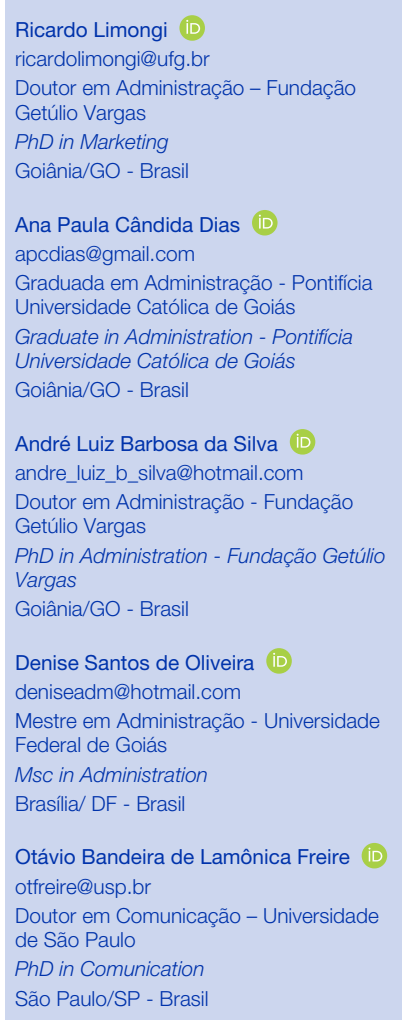


"Sempre fomos referência como atacado. Me lembro de ver nossos outdoors espalhados pela cidade e as reuniões com o conselho focada em como estruturar para receber mais clientes. O pátio aqui do shopping sempre ficou cheio. De um tempo para cá o movimento caiu muito. Nossos lojistas têm sugerido que o orçamento de marketing seja direcionado para o marketing digital. Será que vale a pena? Qual seria o caminho a seguir no digital?" As reflexões do Sr. Isidro, sócio do Shopping Goiás Moda, deixa claro o anseio em mudar a estratégia de divulgação e comunicação com os clientes.

\section{O Caso do Shopping Goiás Moda}

O Shopping Goiás Moda foi inaugurado no ano de 1997, a partir da união de vários empresários do mercado de moda atacadista, e foi instalado na capital do Estado de Goiás, Goiânia. O setor de moda em Goiás é responsável por mais de 200 mil empregos diretos com uma produção mensal de mais de 60 milhões de peças (DANTAS, 2019). De acordo com a ABRASCE (2019), o polo de moda de Goiânia, região em que o Goiás Moda está localizado, contabilizou mais de 9 milhões de visitantes que gastaram entre 3 e 5 mil reais em compras apenas no ano de 2018.

O Goiás Moda especialmente conta com espaço para alocação de 110 lojas com média de $55 \mathrm{~m}^{2}$ cada e comercializadas por aproximadamente 100 mil reais. Estão instaladas no shopping, em sua maioria, lojas de marcas regionais que comercializam um amplo mix de produtos como moda feminina, masculina, infantil, plus-size, jeans, sapatos e acessórios. O público consumidor é composto por revendedores de diferentes regiões do país (principalmente do Centro-Oeste, Norte e Nordeste) que visitam o shopping e adquirem produtos para revender ao consumidor final, em geral, das classes B, C e D.

Desde a inauguração do shopping as estratégias utilizadas pelos gestores para atrair os lojistas e seus consumidores foram baseadas na infraestrutura e divulgação offline. A estrutura física conta com estacionamento, amplos corredores, elevadores, rampas de acesso, iluminação adequada, atmosfera de compra agradável, espaço para alimentação e acesso gratuito à internet. Além de transporte gratuito de clientes para hotéis, aeroporto, rodoviária e outros polos de confecção. 
Já as estratégias de divulgação offline se concentravam, até então, na distribuição de folders impressos na região Centro-Oeste, Norte e Nordeste do país, exposição de outdoors no centro de Goiânia e na utilização de intermediários, que buscavam lojistas interessados na locação das lojas e revendedores de diferentes regiões interessados na compra de produtos comercializados no shopping. Durante alguns anos a gestão do shopping teve sucesso com o uso dessas estratégias. No entanto, durante os anos de 2018 e 2019 foi observada uma queda significativa no número de lojistas no shopping. No período, apenas $60 \%$ das lojas estavam ocupadas, percentual muito baixo se comparado aos anos anteriores e à taxa de ocupação dos demais shoppings atacadistas da região no mesmo período (que esteve entre $70 \%$ e $90 \%)$.

Segundo Isidro, um dos sócios do shopping, a taxa de ocupação é uma de suas principais medidas de resultados. Ele salienta que no ambiente atacadista as vendas são realizadas em grandes quantidades, em uma única ocasião o lojista pode vender de 100 a 1000 peças, assim, não é cobrado um percentual sobre as vendas. A cobrança aos lojistas é baseada exclusivamente na venda da loja (aproximadamente 100 mil reais por loja, mas pago uma única vez) e em uma taxa de condomínio mensal que gira em torno de 600 a 1000 reais. Assim, quanto mais lojas ocupadas, maior o recebimento pela venda e de condomínios e, consequentemente, melhores os resultados financeiros do shopping.

Desta forma, com uma baixa taxa de ocupação e queda nas receitas, o conselho do shopping levantou duas questões para discussão: $O$ que levou à redução na taxa de ocupação do shopping? Como aumentar essa taxa? Isidro se reuniu com os demais sócios para discutir possíveis respostas e direcionamentos a estes questionamentos.

Na discussão um primeiro motivo apontado para redução da taxa de ocupação foi a abertura de novos shoppings atacadistas na região. A cidade de Goiânia é conhecida por ser um dos polos nacionais de moda e, nos últimos anos, houve um intenso aumento no número de shoppings atacadistas - primordialmente na região central da cidade, local onde está localizado o Goiás Moda. Além disso, um segundo motivo levantado foi a forte presença desses novos shoppings no ambiente online, como Facebook, Instagram e outras redes sociais. Os shoppings têm divulgado nas plataformas suas lojas disponíveis para locação e os produtos co- 
mercializados por seus condôminos. Nesse contexto, uma necessidade observada para recuperar a sua taxa de ocupação foi o posicionamento no ambiente online, divulgando não apenas o shopping, mas principalmente os produtos comercializados por seus lojistas. Em geral, os lojistas não possuíam ações individuais para divulgação de seus produtos e acabavam depositando a responsabilidade para a gestão do shopping trazer fluxo de consumidores para suas lojas. O raciocínio empregado foi que se os lojistas ganharem maior visibilidade no ambiente online, então, mais revendedores buscarão o shopping e, consequentemente, mais empreendedores estarão interessados em ocupar suas lojas. Esse então foi o caminho definido: colocar o shopping no ambiente online. Para isso uma nova diretora de marketing foi contratada, Helena.

\section{Vem mudanças por aí...}

Após assumir a diretoria de marketing Helena tinha clareza do objetivo que deveria ser alcançado: levar o shopping para divulgar ações no ambiente online, e claro, aumentar a visibilidade do shopping e de seus lojistas, porém, o "como" ainda não estava definido. Helena atuou como diretora de marketing em diversos outros segmentos, principalmente imobiliário e educacional, mas não tinha atuado no mercado de moda. Nas primeiras semanas se dedicou a levantar informações sobre o mercado de moda, visitar os shoppings atacadistas da região, conversar com os outros diretores do shopping e com os lojistas para compreender melhor as dificuldades e demandas dos consumidores. Esses levantamentos foram realizados para basear o plano estratégico a ser desenvolvido em seguida, e ainda, ações que pudessem ter resultados mais rápidos.

Depois, a nova diretora se encontrou com a gerente de inteligência de mercado do shopping, Adriana, que trouxe informações sobre o funcionamento do mercado da moda. Segundo Adriana existem dois importantes tipos de semanas de moda que guiam as peças que serão comercializadas nas próximas estações ou coleções: (a) haute couture, ou alta costura, representada por peças mais exclusivas de produção à mão e, (b) prêt-à-porter, representada por peças produzidas em maior escala industrial. 
As semanas Haute Couture são formadas por peças mais exclusivas voltadas geralmente ao mercado de casamentos, festas de gala e grandes eventos sociais. No Brasil não é comum esse tipo de semana de moda, e um dos motivos pode ser devido a grandes marcas internacionais, consideradas de alta costura, não investirem significativamente no país. Em Paris, por exemplo, na semana Haute Couture as marcas que participam são selecionadas por uma comissão que avalia e supervisiona aquelas que estão aptas a produzir as peças com a alta qualidade exigida. O segundo tipo de semana de moda existente, e mais comum, é o prêt-à-porter. Se trata de semanas de moda nas quais são apresentadas peças produzidas em mais larga escala, geralmente as coleções são correlacionadas com as estações do ano: primavera/verão e outono/inverno. As semanas mais famosas desse tipo são as de Nova York, Londres, Milão e Paris. No Brasil também existem algumas semanas nesses moldes como a São Paulo Fashion Week. Especialmente em Goiânia esse tipo de semana também acontece anualmente e representa o maior desfile do centro-oeste brasileiro tendo, em geral, quatro dias de evento.

Essas semanas definem tendências de cores, tecidos e formas que serão comercializadas nos meses seguintes. As prêt-à-porter, principalmente, guiam as tendências no mundo fast fashion - modalidade de consumo comercializada pelos lojistas do shopping - como o próprio nome já diz ("moda rápida" em português) se trata de peças que necessitam chegar ao consumidor rapidamente senão a "moda passa". Comumente os lojistas do shopping enviam seus estilistas às semanas prêtà-porter, realizadas no Brasil ou no exterior, para se anteciparem das tendências da próxima estação. Essa necessidade de acompanhar de perto essas semanas é justificada devido à criação e divulgação de novas tendências necessitarem de agilidade, ainda mais no comércio atacado. Os lojistas acompanham as tendências futuras o quanto antes para levá-las ao revendedor e, por sua vez, passá-las em tempo hábil para o consumidor final. Assim, mesmo se tratando de um negócio com foco no mercado atacadista, para Adriana, a estratégia a ser utilizada pelo shopping deveria levar em conta a orientação ao consumidor final. Adriana apontou ainda para Helena que em conversa com vendedores dos lojistas foi mencionado que os consumidores ficam antenados em blogs de moda, perfis no Instagram e novelas para inspirarem seus visuais. 
Com essa conversa Helena pensou que a melhor estratégia seria seguir a lógica inversa para atrair mais lojistas ao shopping, isto é, atraindo inicialmente o consumidor final (como apresentado na Figura 1). O shopping focaria em atrair a atenção do consumidor final para as peças e marcas comercializadas, assim, buscariam essas peças junto aos revendedores, que precisariam buscá-las com os lojistas do shopping. Com o aumento na atratividade e nas vendas dos atuais lojistas, e claro, no fluxo de revendedores dentro do shopping, a expectativa era que novos empreendedores seriam atraídos a instalar as suas lojas no Goiás Moda.

Figura 1 Relacionamento do consumidor final até as lojas o shopping

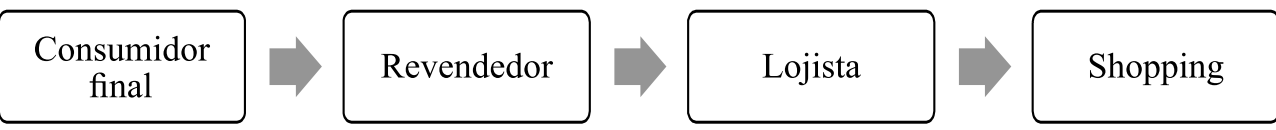

Fonte: Elaborado pelos autores.

A questão agora seria como atrair o consumidor final. Em conversa com os atuais lojistas do shopping Helena identificou que o aumento no nível de acesso à internet possibilitou aos revendedores acompanharem mais rapidamente as tendências mundiais da moda. É comum, segundo esses lojistas, os revendedores procurarem roupas vistas em blogs ou perfis de influenciadores seguidos pelos seus consumidores finais. A partir disso, Helena ficou se questionando: seria então, o uso de influenciadores um bom caminho? Afinal os lojistas e os consumidores estão se inspirando neles.

Para auxiliá-la a responder essa pergunta a gerência de inteligência de mercado, liderada por Adriana, realizou uma pesquisa sobre diversos influenciadores digitais. Na pesquisa realizada foram encontrados inúmeros nomes como Bruna Marquezine, Camila Coelho e Thassia Naves. Bruna Marquezine, por exemplo, apenas no Instagram tinha 33,8 milhões de seguidores em 2018 e divulgava diferentes marcas, tanto nacionais quanto internacionais, despertando interesse pelos produtos e marcas em diversos perfis de consumidores. Em uma única postagem, realizada para a marca Puma, Bruna obteve aproximadamente 910 mil curtidas e quase 6500 comentários. No entanto, Helena e Adriana sabiam que uma campanha 
com uma celebridade como Bruna Marquezine seria inviável levando em conta a realidade financeira do shopping.

O Instagram, rede social analisada pela equipe de Adriana, tem se apresentado como uma das redes sociais com maior taxa de crescimento na América Latina (STATISTA, 2020). No ano de 2018, seis em cada dez adultos latino americanos tinham uma conta no Instagram. Esta rede, no contexto global, atingiu a marca de 1 bilhão de usuários mensais, 400 milhões de visualizações diárias nos stories, e 25 milhões de empresas ativas. Observou-se que o gasto com influenciadores digitais no Instagram tem aumentado ano a ano mundialmente. Em 2017 os gastos globais foram de 4,17 bilhões de dólares, enquanto no ano seguinte, 2018, de 5,67 bilhões (STATISTA, 2018).

Com a visualização desses números Helena percebeu que cada vez mais as marcas têm investido na divulgação dos seus produtos por meio do Instagram e utilizado nesta rede influenciadores digitais. Assim, esse caminho lhe pareceu promissor para atrair consumidores às marcas do segmento de moda atacado. $O$ ponto central agora seria conseguir equilibrar as limitações orçamentárias da área de marketing do Goiás Moda com os custos para contratação de influenciadores digitais. O orçamento mensal da área era baixo, em torno de 10 mil ao mês para as ações de marketing, e o custo para contratação de influenciadores digitais era aparentemente elevado.

\section{Bem-vinda ao universo dos Influenciadores Digitais}

Helena, até então, não havia trabalhado com influenciadores digitais, por isso, contratou uma agência de publicidade para auxiliá-la no processo de escolha e contratação desses influenciadores. De acordo com a equipe da agência o mercado dos influenciadores digitais no Brasil é amplo. Há inúmeras classificações de influenciadores utilizadas, são elas:

- $\quad$ Celebridades: exercem funções significantes fora das plataformas digitais, como modelos, atores, atletas ou apresentadores, e são mais vistos como um canal de divulgação ou endosso na co-criação com as marcas; 
- Influenciadores: perfis maiores em números de seguidores que apresentam temas mais genéricos como comportamento, cotidiano, moda e beleza. Eles também trabalham na co-criação de conteúdo com as marcas;

- Micro-influenciadores: perfis menores que, geralmente, abordam assuntos de nichos co-criando também conteúdo com as marcas.

No processo de contratação, de acordo com a equipe da agência, os influenciadores encaminham um press kit com a média de engajamento e alcance de suas postagens, estas informações de desempenho das postagens são disponibilizadas pelo próprio Instagram (ex.: número de visualizações, curtidas, comentários e salvamentos). Embora haja influenciadores com alto nível de desempenho de suas postagens a agência levantou várias barreiras para atuar com os influenciadores. Dentre elas está a confiabilidade das informações prestadas, pois não há como assegurar que os dados apresentados são 100\% confiáveis, há possibilidade de uso de perfis fakes, compra de seguidores, entre outros problemas. Assim, é necessária uma escolha cautelosa desses influenciadores. Além disso, uma outra barreira era a questão financeira pois os recursos financeiros disponíveis eram insuficientes para atuar com os maiores nomes desse segmento (contratos que chegam a superar 100 mil reais ao mês). Todos esses aspectos deveriam ser pensados para que Helena apresentasse a proposta de atuação com influenciadores digitais ao conselho gestor do shopping e tentasse convencê-los a realizar o investimento. Nesse sentido, Helena solicitou à agência uma proposta para contratação de influenciadores digitais e estratégias de como poderia atuar para atender a demanda dos atacadistas considerando as restrições orçamentárias do shopping.

O retorno esperado desta ação com influenciadores seria somente para o ano de 2019, não estava mais no roadmap de 2018. Após realizar alguns estudos, a agência mostrou que a contratação de influenciadores ocorre em parceria com diversas empresas e segmentos, mas alertou sobre os custos elevados desta estratégia e sobre as dificuldades de indicadores para acompanhar os resultados nas vendas e no fluxo de clientes para os atacadistas. A agência explicou ainda que além da contratação do influenciador digital é preciso considerar o investimento para a confecção das fotos que serão veiculadas em postagens no perfil do shopping e do 
influenciador, o deslocamento para as ações, o impulsionamento nas redes sociais e no Google, e a necessidade do envolvimento dos lojistas.

A alternativa mais aderente à realidade do shopping, de acordo com a agência, seria a contratação de micro-influenciadores por apresentarem melhores resultados por serem menores e terem hábitos de vida e comportamentos mais próximos aos consumidores. Além disso, Adriana (gerente de inteligência) reforçou que seus estudos demostravam também que este perfil de influenciador possui um maior grau de engajamento (relação entre número de seguidores e quantidade de curtidas e comentário) do que os influenciadores e as celebridades, e claro, é mais viável financeiramente para pequenas empresas com orçamento restrito, como é o caso do shopping.

Os dados apresentados pela agência mostraram ainda que desde o ano de 2017 os chamados micro-influenciadores, com uma média entre 50 e 250 mil seguidores, apresentaram bom desempenho em divulgações (alto número de visualizações, curtidas e comentários nas divulgações realizadas de marcas patrocinadas). A agência reforçou para Helena que cada micro-influenciador possui a sua plataforma pessoal e tem uma base de usuários com alcance que, se bem trabalhado, pode ser relevante. Principalmente em função do baixo custo, há a possibilidade de utilizarem um maior número de influenciadores ampliando as regiões do país alcançadas. Desta forma, a diretora de marketing em conjunto com o conselho gestor analisaram o cenário, e decidiram aprovar a estratégia de divulgação com os micro-influenciadores como a primeira estratégia no ambiente online do shopping. Consideraram ainda o uso de influenciadores com perfis maiores para ampliar a divulgação em regiões mais desenvolvidas. Nessas regiões e eventos que seriam promovidos seria possível obter um orçamento mais amplo para a área de marketing. A questão agora seria: quais influenciadores contratar?

\section{O Processo de Escolha e Contratação dos Influenciadores}

Após a aprovação, a agência de marketing iniciou seu estudo para escolher os influenciadores que apresentavam congruência com a imagem do shopping e de seus lojistas. Inicialmente, a agência mapeou as regiões chaves do Brasil para 
direcionar a estratégia de comunicação online, que foram: Centro-Oeste, Norte e Nordeste. Em seguida, definiu os Estados que seriam foco e realizou uma busca dos perfis de influenciadores que atendiam aos requisitos destes Estados, levando em consideração os aspectos estéticos em relação aos segmentos de lojas que atuam dentro do shopping. Assim, foram listados perfis para compor o time de influenciadores, e a partir da análise da taxa de engajamento (relação entre número de seguidores e medidas de interação com a publicação) e da adequação à proposta do shopping foram selecionados os perfis mais adequados.

Ao todo foram apresentados onze influenciadores que poderiam atuar como canal de divulgação do shopping no Instagram ao longo de um ano. A ideia seria utilizar esses influenciadores em diferentes eventos promovidos pelo shopping ao longo do ano para atrair os consumidores. As informações dos influenciadores considerados mais adequados estão listadas na Tabela 1:

Tabela 1 Informações dos influenciadores digitais com perfil adequado para divulgação do shopping e dos lojistas - dados de 2018

\begin{tabular}{|c|c|c|c|c|}
\hline $\begin{array}{l}\text { Influen- } \\
\text { ciador(a) }\end{array}$ & Perfil & $\begin{array}{l}\text { Estado de } \\
\text { Atuação }\end{array}$ & $\begin{array}{l}\text { No de Se- } \\
\text { guidores }\end{array}$ & $\begin{array}{l}\text { Taxa de en- } \\
\text { gajamento }\end{array}$ \\
\hline 11 & $\begin{array}{l}\text { Mulher, branca, entre } 30 \text { e } 40 \\
\text { anos, cabelos loiros, estilo mais } \\
\text { sofisticado, divulga vestidos, } \\
\text { joias e roupas sociais. }\end{array}$ & São Paulo & $825 \mathrm{mil}$ & $0,88 \%$ \\
\hline 12 & $\begin{array}{l}\text { Mulher, morena, entre } 20 \text { e } 30 \\
\text { anos, cabelos castanhos, mode- } \\
\text { lo plus size, divulga moda praia, } \\
\text { fitness, lingeries, vestidos, entre } \\
\text { outros. }\end{array}$ & $\begin{array}{l}\text { Distrito } \\
\text { Federal }\end{array}$ & $89,1 \mathrm{mil}$ & $1,51 \%$ \\
\hline 13 & $\begin{array}{l}\text { Mulher, branca, entre } 30 \text { e } 40 \\
\text { anos, cabelos loiros, divulga ves- } \\
\text { tidos, roupa social, sapatos, entre } \\
\text { outros }\end{array}$ & Goiás & $111 \mathrm{mil}$ & $2,52 \%$ \\
\hline
\end{tabular}


Mulher, morena, entre 20 e 30 anos, cabelos castanhos, divulga moda praia, acessórios, vestidos,

São Paulo 286 mil $^{*} \quad 1,04 \%$ entre outros.

\section{Criança, entre 5 e 10 anos, bran-}

15 ca, cabelos castanhos, divulga roupas infantis

\section{Rio Grande}

do Sul 208 mil $1,00 \%$ Duas mulheres, uma loira e outra morena, entre 30 e 40 anos, estilo

I6 mais sofisticado, divulgam maquiagem, roupas sociais, esporte

\section{Maranhão}

e Piauí $86,5 \mathrm{mil}$ $2,55 \%$ fino e sapatos.

Mulher, morena, entre 20 e 25

17 anos, cabelos castanhos, divulga moda praia, fitness, lingeries, Goiás 104 mil $1,81 \%$ jeans, entre outros.

Mulher, morena, entre 20 e 30

18 anos, cabelos castanhos, divulga moda praia, acessórios, vestidos, Mato Grosso $\quad 79,7 \mathrm{mil} \quad 2,11 \%$ entre outros.

Mulher, morena, entre 20 e 30

19 anos, cabelos pretos, divulga moda praia, fitness, jeans, entre Pará 156 mil $2,62 \%$ outros.

Mulher, morena, entre 20 e 30 110 anos, cabelos castanhos, estilo despojado, divulga vestidos, Alagoas $2,1 \mathrm{mi}-$ Ihões $1,69 \%$ jeans, roupa social, entre outros. Homem, moreno, entre 20 e 30

111 anos, cabelos pretos e curtos, diGoiás 233 mil $1,46 \%$ vulga moda masculina em geral.

Legenda: ( $\left.{ }^{*}\right)$ Embora tenha ultrapassado 250 mil seguidores, o perfil ainda estava dentro da categoria de micro-influenciador.

Fonte: Elaboração pelos autores com base em informações coletadas no Instagram. 
$\mathrm{Na}$ listagem da Tabela 1 são apresentados influenciadores com diferentes perfis, sendo: nove mulheres, um homem e uma criança. Neste conjunto escolhido, apenas dois nomes fugiram significativamente do padrão de até 250 mil seguidores no Instagram: I1 e I10. Essas duas influenciadoras poderiam ser contratadas especialmente para atuação nos eventos semestrais que aconteciam no shopping. Os demais influenciadores poderiam atuar no calendário comum do shopping, de janeiro a dezembro, e o custo médio de cada micro-influenciador (incluindo ensaio, viagens se necessárias, hospedagem e os demais custos) era entre 5 e 10 mil reais por mês.

A decisão tomada foi contratar um micro-influenciador por mês. Assim, o shopping poderia atingir os públicos definidos e cumprir, ao mesmo tempo, o orçamento mensal. Após a definição dos nomes de influenciadores os passos adotados entre Helena e agência foram:

1. alinhar o perfil dos produtos e marcas comercializados no shopping com o de cada influenciador;

2. verificar a quantidade de postagens patrocinadas que seriam adquiridos a partir desse ajuste, considerando que cada publicação aumentava o custo de contratação do influenciador, os gastos para fotos, dentre outros custos;

3. definir o local em que a campanha seria produzida, e

4. estabelecer qual o conteúdo dos stories a serem gerados pelos contratados.

Os pontos foram discutidos e individualizados a cada influenciador e ao mês em que ação ocorreria. Assim, definiu-se que seriam realizadas entre 10 a 20 postagens de fotos ao mês, excepcionalmente seriam publicados vídeos. Os locais das campanhas seriam diversos e nem todas as campanhas teriam o acompanhamento de stories no perfil do shopping ou do influenciador.

Com esses dados em mãos os contratos foram elaborados pela equipe jurídica do shopping. Após a conclusão dos detalhes burocráticos a empresa responsável pela produção da filmagem e fotografia do material foi acionada. Mesmo nos casos em que a execução do material era do influenciador digital a curadoria 
das peças enviadas era sempre de responsabilidade do shopping. Apenas um dos contratos assinados teve essa característica de o material ser produzido pela influenciadora por ter sido executado em Nova lorque, durante uma semana de moda prêt-à-porter da cidade.

\section{Engajamento e seguidores alcançados. Problemas resolvidos?}

Os contratos dos influenciadores digitais para promoção do Shopping Goiás Moda estavam na reta final. Após 12 meses, já tinham dados suficientes para analisar e definir os próximos passos. Agora era a hora de compilar os resultados. A agência compilou as informações e convidou Helena e sua equipe para apresentação dos resultados alcançados. A agência havia combinado com Helena que levantaria o total de postagens, quantidade de curtidas e comentários por influenciador contratado. Os resultados, conforme a Tabela 2, demostraram que a estratégia de contratar influenciadores gerou forte engajamento nas redes sociais. Com 152 postagens realizadas foram obtidas 315.558 mil curtidas e quase 5 mil comentários nas postagens.

Tabela 2 Resultados da Campanha de Marketing Digital

\begin{tabular}{|cccc|}
\hline Influenciador & $\begin{array}{c}\text { Total de } \\
\text { Postagens }\end{array}$ & $\begin{array}{c}\text { Total de } \\
\text { Curtidas }\end{array}$ & $\begin{array}{c}\text { Total de } \\
\text { Comentários }\end{array}$ \\
\hline I1 & 1 & 26.087 & 921 \\
\hline I2 & 2 & 13.427 & 117 \\
\hline I3 & 4 & 3.641 & 78 \\
\hline 14 & 8 & 6.645 & 198 \\
\hline 15 & 8 & 12.718 & 208 \\
\hline 16 & 12 & 37.283 & 433 \\
\hline 18 & 13 & 32.633 & 426 \\
\hline 19 & 18 & 45.768 & 579 \\
\hline
\end{tabular}




\begin{tabular}{|cccc|}
\hline 110 & 19 & 31.316 & 187 \\
\hline I11 & 33 & 59.958 & 782 \\
\hline Total & $\mathbf{1 5 2}$ & $\mathbf{3 1 5 . 5 5 8}$ & $\mathbf{4 . 9 5 3}$ \\
\hline
\end{tabular}

Fonte: Elaboração pelos autores com base em informações coletadas com gestores do Shopping e a Agência.

Uma informação apresentada pela agência incomodou Helena e sua equipe, a taxa de engajamento proporcionada pelas postagens por cada influenciador (Gráfico 1). Foi identificado que apenas $63 \%$ das postagens atingiram taxa de engajamento (a relação entre comentários, curtidas sobre impressões) acima de $2 \%$. A taxa de engajamento de alguns influenciadores ficou abaixo de $1 \%$.

Gráfico 1 Taxa de Engajamento por Influenciador

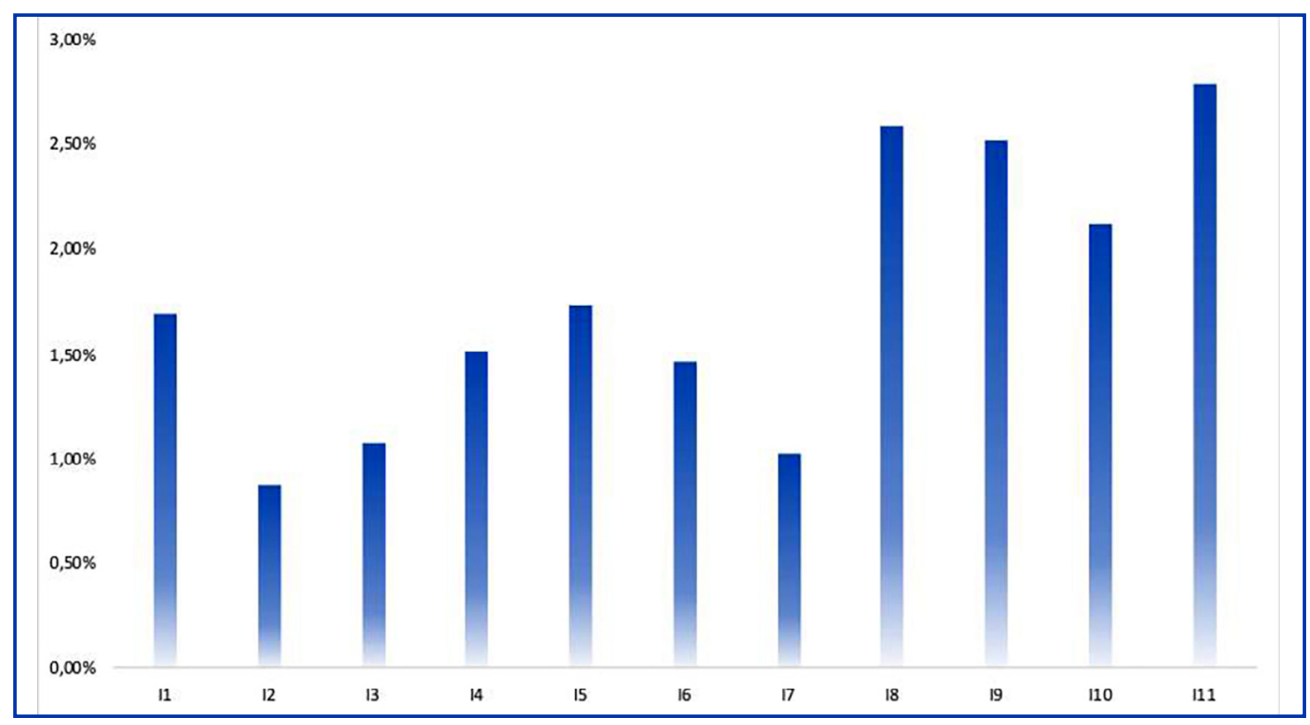

Fonte: Elaboração pelos autores com base em informações coletadas com gestores do Shopping e a Agência.

A agência explicou que a taxa de engajamento abaixo de $2 \%$ era uma porcentagem aceitável para um primeiro projeto já que o shopping nunca tinha desenvolvido estratégias no ambiente online, porém, a resposta não convenceu Helena. A diretora argumentou que grande parte do orçamento para marketing foi direcionado 
para esta estratégia e esperava uma taxa maior de retorno em relação ao engajamento. A agência argumentou que o shopping não tinha nenhuma informação que os ajudassem na escolha dos influenciadores e estavam iniciando suas estratégias digitais. Agora, ao final do projeto, já tinham informações suficientes para saber o que funcionava de forma efetiva e era o momento de refinar a escolha dos novos influenciadores para as próximas etapas.

Para reforçar a argumentação em relação ao engajamento a agência mostrou o gráfico de evolução dos seguidores. Quando iniciaram a estratégia no Instagram, o shopping possuía 3.436 mil seguidores, um número relativamente baixo quando comparado com o volume de clientes e a capacidade de atração. Após a implementação da estratégia digital, ao longo de 12 meses, a agência levantou que o número de seguidores saltou de 3.436 mil para 12.174 mil seguidores, conforme apresentado no Gráfico 2. Então a agência reforçou novamente: "Agora temos informações necessárias para construir nossa estratégia no ambiente online e alinhar com as estratégias offline do shopping!"

\section{Gráfico 2 Evolução do número de seguidores}

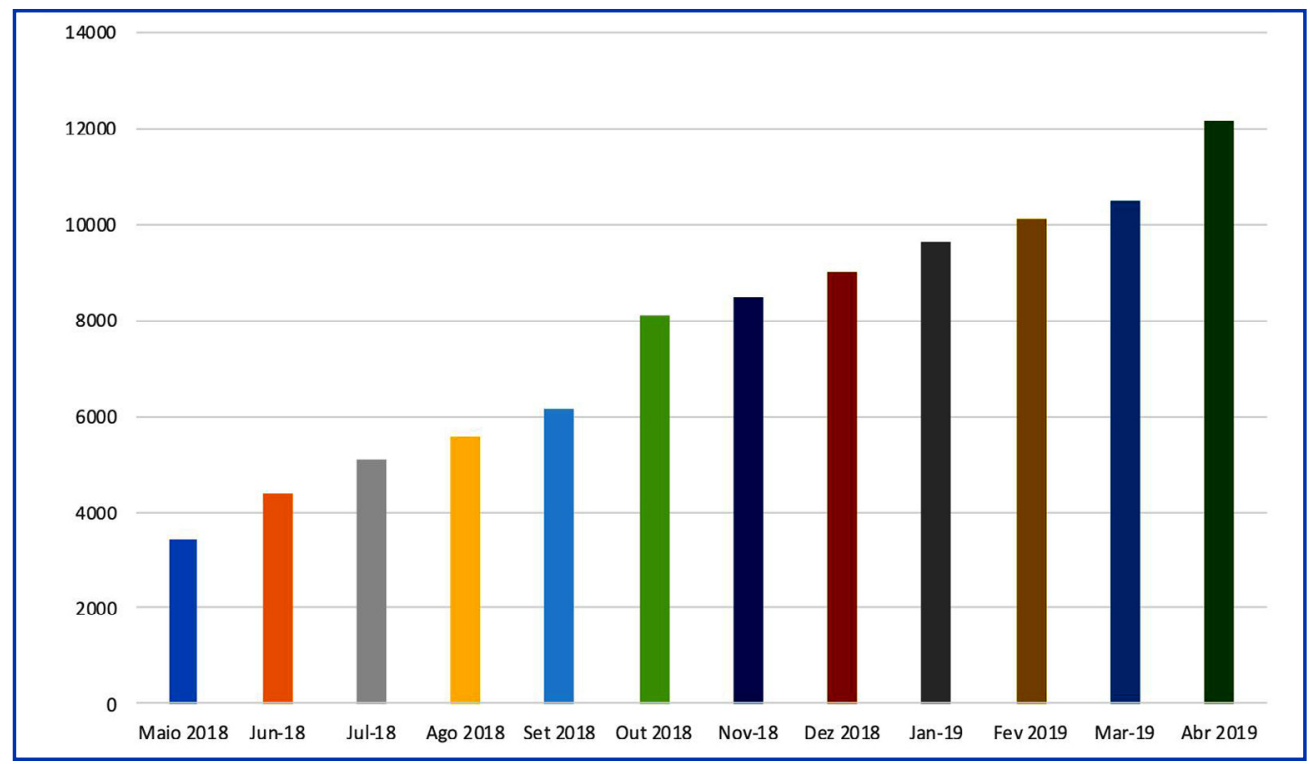

Fonte: Elaboração pelos autores com base em informações coletadas com gestores do Shopping e a Agência. 
Helena comentou que gostou, mas que agora deveria retornar e conversar com o conselho gestor do shopping e apresentar estes resultados. No entanto, claramente ainda estava incomodada com as taxas de engajamento, afinal, achou baixa pelo valor investido em relação ao orçamento que tinha à disposição. Outro ponto, que não foi discutido na reunião e não foi analisado pela agência, era a relação entre a estratégia de influenciadores e a taxa de ocupação do shopping. Não foi avaliado se a estratégia beneficiou o shopping e os lojistas de alguma forma. Helena já sabia que seria questionada e teria que justificar ao conselho gestor. Como o aumento de curtidas, seguidores e comentários nas postagens com os influenciadores gerou benefícios para o shopping? E para os lojistas?

\section{Notas de Ensino}

\section{FONTE DOS DADOS}

O caso foi construído a partir da discussão com a agência responsável pelo marketing e os gestores do shopping. As entrevistas com a agência tiveram início com um grupo de pesquisa em marketing e comportamento do consumidor visando identificar as práticas de marketing em empresas de pequeno porte. A partir das entrevistas iniciais e delimitação dos dados levantados durante a transição da comunicação do ambiente offline para o online, os autores entrevistaram a administração do shopping que inspirou este caso, bem como, analisou os dados históricos de engajamento das redes sociais antes e depois da contratação dos influenciadores digitais para apresentar esta nova estratégia de divulgação.

\section{OBJETIVOS EDUCACIONAIS}

O caso é apropriado para ser utilizado nos cursos de graduação em Administração, Publicidade e Propaganda, tecnólogos em marketing, gestão de negócios e moda, bem como, especialização nas diferentes temáticas de gestão. Além destes cursos, é recomendada a utilização em disciplinas de Marketing e Comunicação, afinal, o caso instiga a discussão sobre a gestão em pequenas empresas, o uso de estratégias de marketing digitais, inclusão e comunicação de influenciadores digitais, critérios de seleção desses influenciadores digitais e mensuração de resultados. 
Do "Off" ao "On" no Mercado Atacado de Moda: o Potencial de Influenciadores Digitais

From Off to On in the Wholesale Fashion Market: the Potential of Digital Influencers

Ricardo Limongi | Ana Paula Cândida Dias | André Luiz Barbosa da Silva | Denise Santos de Oliveira

Otávio Bandeira de Lamônica Freire

\section{UTILIZAÇÃO DO CASO}

É recomendada a aplicação do caso da seguinte forma como apresentado no Quadro 1:

Quadro 1 Tempo de Aplicação do Caso de Ensino

\begin{tabular}{|c|c|}
\hline $\begin{array}{ll}\text { Etapa } & \text { Tempo } \\
\text { Estimado }\end{array}$ & Atividade \\
\hline
\end{tabular}

$1 \quad 0-30 \mathrm{~min} \quad$ Leitura e análise individual pelo aluno (antes da aula)

Preparação

Discussão em pequenos grupos (entre três

$2 \quad 0-15$ min e cinco alunos) para debate do tema e po- Contexto sicionamento de opiniões

\begin{tabular}{|c|c|c|c|}
\hline 3 & $15-30 \mathrm{~min}$ & $\begin{array}{l}\text { Apresentação pelo professor de exemplos } \\
\text { de influenciadores digitais nacionais e in- } \\
\text { ternacionais de diferentes segmentos para } \\
\text { análise do impacto na decisão do consu- } \\
\text { midor, e ainda, elaboração da persona }\end{array}$ & $\begin{array}{c}\text { Marketing e } \\
\text { Influenciadores } \\
\text { Digitais }\end{array}$ \\
\hline 4 & $20-40 \mathrm{~min}$ & $\begin{array}{l}\text { Elaboração e Apresentação do Social Me- } \\
\text { dia Canvas }\end{array}$ & Planejamento \\
\hline 5 & $0-10 \min$ & $\begin{array}{l}\text { Apresentação e Discussão Final do Social } \\
\text { Media Canvas Elaborado }\end{array}$ & Fechamento \\
\hline
\end{tabular}

Fonte: Elaborado pelos autores

Além do caso é recomendado que os alunos façam a leitura de dois artigos previamente: Coelho et al. (2017) e de Almeida et al. (2018). É esperado com a leitura os alunos possam compreender diferentes aplicações dos influenciadores pela área de marketing.

A expectativa com o caso é fomentar aspectos como:

- Discussão sobre a relevância da integração de estratégias de marketing offline e online; 
- Reflexões quanto ao uso de influenciadores digitais na divulgação das ações comerciais em pequenas empresas;

- Apresentar a realidade da limitação de gastos com o marketing e a necessidade de divulgação das lojas de um shopping atacadista;

- Importância do retorno de investimento em marketing pelas micro e pequenas empresas;

- Incentivar a discussão sobre métricas de retorno das ações comerciais dos influenciadores digitais;

- Estimular docentes e discentes, por meio de um caso real, a avaliar estratégias de marketing digital no contexto de pequena empresa.

\section{PLANO DE ENSINO SUGERIDO}

Para o melhor aproveitamento da temática de gestão de marketing e do uso de influenciadores digitais como estratégias de marketing o docente poderia organizar a discussão em três momentos:

a. identificação das necessidades do shopping;

b. análise da possibilidade de utilizar influenciadores digitais para atender o objetivo pretendido;

c. discussão sobre os diferentes perfis e tipos de conteúdo utilizados pelos influenciadores digitais;

d. elaboração da jornada de compra do consumidor para identificar a etapa em que o influenciador digital poderia impactar; e

e. promover a formalização da estratégia dos influenciadores digitais por meio do Social Media Canvas.

Recomendamos que o docente discuta estratégias de marketing praticadas por shoppings e lojas de moda, e apresente perfis e números de engajamento dos principais influenciadores digitais no Brasil. Poderia utilizar o site SocialBakers como referência, tanto para o Brasil como outras regiões, para destacar os diferentes perfis e conteúdos utilizados. Posteriormente, com o apoio dos discentes o docente montaria uma persona do consumidor de varejo de moda, assim, as demais atividades do caso estariam alinhadas para o trabalho em grupo pelos discentes. É 
recomendável considerar na criação da persona a jornada do consumidor de moda por meio das seguintes etapas: os fatores iniciais que o consumidor considera para comprar; as avaliações que os consumidores fazem para as compras; os pontos de contato entre consumidor e marca; elementos presentes no momento da compra; e por fim, o pós compra.

Por fim, o docente recomendaria que cada grupo preenchesse o Social Media Canvas (Figura 2), disponível impresso em tamanho A3, para que os grupos pudessem montar a estratégia a ser utilizada pelo shopping atacadista no uso dos influenciadores digitais nos diferentes canais de redes sociais como estratégia de marketing. O recomendado nessa etapa é que o professor oriente até 40 minutos para que os grupos possam trabalhar. Após o preenchimento do Social Media Canvas pelos alunos, o docente solicitaria que cada grupo apresentasse as estratégias desenvolvidas em até 10 minutos, e poderia concluir discutindo as dificuldades em otimizar as campanhas, gastos e mensuração do resultado.

Figura 2 Social Media Canvas para preenchimento

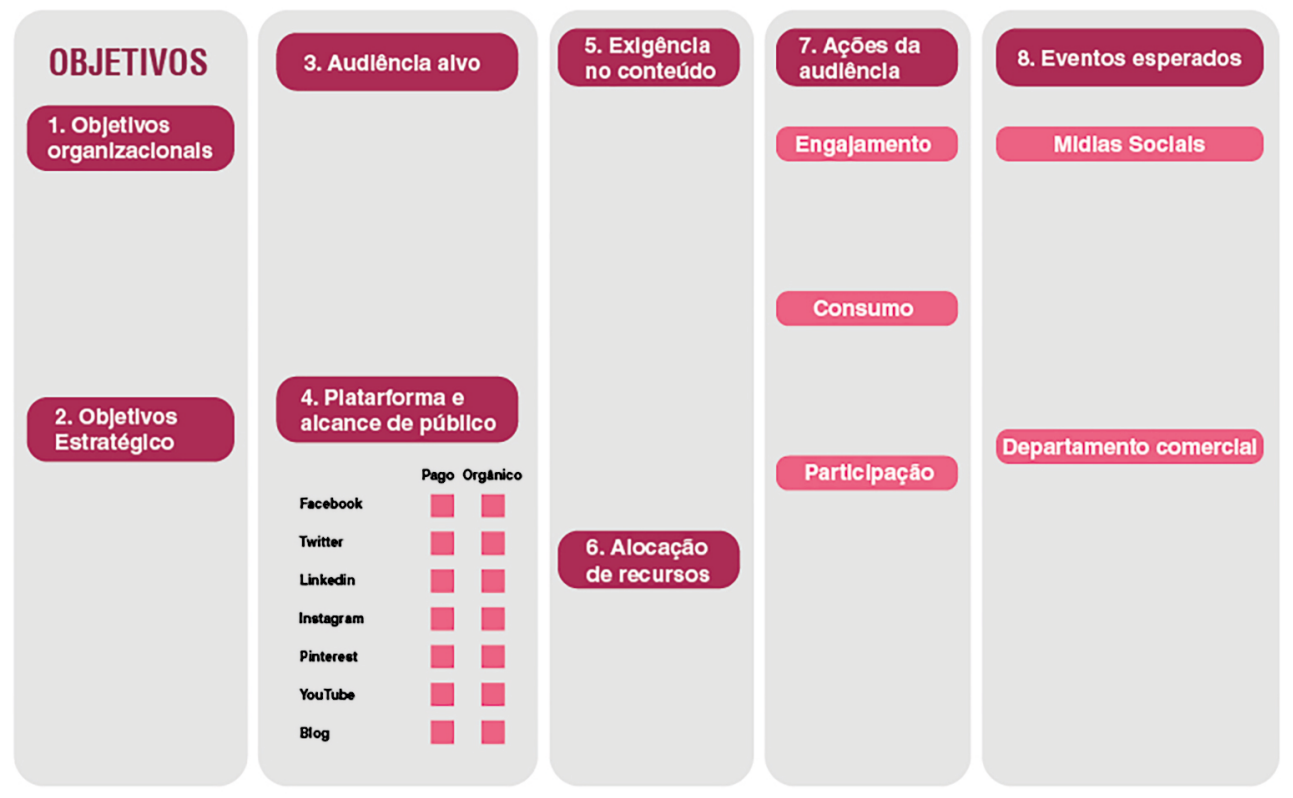

Fonte: Orange Clube Group (2020) 


\section{QUESTÕES PROPOSTAS E POSSÍVEIS DIRECIONAMENTOS PARA DISCUS- SÃO DO CASO}

Para nortear as discussões a partir da leitura do caso e do preenchimento do Social Media Canvas, recomendamos as seguintes questões e os respectivos direcionamentos com os alunos:

1. Quais os maiores desafios na implementação de estratégias de marketing offline e online no Shopping Goiás Moda?

Ao longo do texto são apresentados diversos desafios enfrentados, dentre eles:

A falta de experiência dos gestores do Shopping Goiás Moda com estratégias de marketing online. As estratégias de marketing anteriormente utilizadas pelos gestores eram exclusivamente offline como a distribuição de folders, a exposição de outdoors ao longo da cidade e a utilização de intermediários. No estudo realizado por Coelho et al. (2015) se observa que em pequenas empresas, geralmente, a definição de estratégias é baseada no feeling dos gestores. Houve a contratação de uma nova diretora de marketing, contudo, a experiência vem de um contexto diferente da moda. Talvez esta falta de experiência tenha levado o maior dispêndio de tempo para iniciar a implementação das estratégias online;

Estruturação de uma estratégia no ambiente on-line para atrair novos lojistas. Chegar, de modo direto, aos lojistas foi um desafio enfrentado por Helena. A alternativa encontrada foi seguir uma lógica inversa, isto é, atrair primeiro o consumidor final e toda a cadeia até chegar aos empreendedores que se interessariam em estabelecer lojas no shopping;

Limitação orçamentária da área de marketing. O orçamento mensal da área era restrito, o que limitou a implementação de estratégias. Helena precisou desenvolver uma estratégia mais enxuta, com o uso primordialmente de micro-influenciadores, para atender ao orçamento estabelecido. 
2. Em sua opinião, as informações levantadas por Helena demonstram que a contratação de influenciadores digitais seria uma boa estratégia para alcançar o objetivo pretendido por Helena? Por quê?

Sim, as informações levantadas por Helena e Adriana demostram que a contratação de influenciadores é um caminho interessante para alcançar o objetivo pretendido: aumentar a taxa de ocupação das lojas. Helena esperava que as ações com influenciadores digitais iriam inicialmente atrair o consumidor final às peças e marcas comercializadas no shopping, em seguida, aumentar a busca dessas peças pelos revendedores, aumentar as vendas dos atuais lojistas e o fluxo de revendedores dentro do shopping e, por fim, atrair novos empreendedores a instalar suas lojas no shopping. Assim, se trata de uma estratégia indireta para alcançar o objetivo pretendido, mas que se monstra plausível.

3. Quais seriam as principais contribuições dos influenciadores digitais para o Shopping Goiás Moda?

A concepção de Helena era que as ações com influenciadores digitais poderiam apresentar resultados diversos, que abrangem a cadeia apresentada na Figura 1 (do consumidor final aos novos empreendedores que se interessariam em instalar lojas no shopping). Mais especificamente os influenciadores digitais iriam contribuir para:

- Atrair o consumidor final às peças e marcas comercializadas no shopping levando-os a buscá-las junto aos revendedores;

- Aumentar o fluxo de revendedores dentro do shopping;

- Potencializar o nível de vendas dos lojistas;

- Elevar a popularidade do shopping e de seus lojistas no meio online levando, por exemplo, ao aumento no número de seguidores em seus perfis do Instagram, número de cliques em seus sites e buscas no Google.

- Aumentar o número de empreendedores que se interessam por instalar suas lojas dentro do shopping; e

- Elevar a taxa de ocupação das lojas. 
4. Caso você fosse o gestor do Shopping Goiás Moda quais critérios adotaria para escolha dos influenciadores digitais?

Helena considerou contratar micro-influenciadores regionais baseando-se no perfil de cada um deles, Estado de atuação, número de seguidores e taxa de engajamento. Outros critérios que poderia ser utilizado seriam:

- Empatia do influenciador. Proxies dessa medida poderiam ser o número de marcações do influenciador em perfis de terceiros e média de comentários positivos recebidos em cada publicação;

- Métricas de popularidade regional, como número de seguidores no Estado de atuação, número de curtidas e comentários realizados pelos seguidores. A inclusão desse critério seria importante para avaliar se, de fato, o influenciador apresenta influência no Estado em questão;

- Número ou intensidade de crises de imagem nos últimos anos.

5. Como o resultado das ações com os influenciadores digitais poderia ser mensurado?

Para uma melhor mensuração da estratégia é preciso ressaltar a importância do registro de informações para acompanhamento de resultados uma vez que estudos demonstram a fraca estruturação de resultados em micro e pequenas empresas (COELHO et al., 2014). No caso do Shopping Goiás Moda, os dados foram estruturados pela agência de marketing em planilhas de Excel. Os resultados das ações poderiam ser mensurados por meio de medidas como:

- Número de seguidores no perfil do shopping e dos lojistas no Instagram;

- Número de acessos em seus sites;

- Taxa de engajamento nas publicações realizadas pelo shopping e lojistas;

- Volume de vendas dos lojistas;

- Nível de procura de lojas por novos empreendedores;

- Taxa de ocupação das lojas. 
6. Quais seriam as perspectivas de adoção dos canais digitais para divulgação do shopping no contexto de pós pandemia?

A discussão do caso, bem como a coleta dos dados, ocorreu antes da pandemia mundial do COVID-19. Porém, é recomendável que seja discutido com os alunos o comportamento dos consumidores de moda pós pandemia. Uma discussão relevante seria compreender a alteração do processo de compra dos revendedores e consumidores de moda a partir dos canais digitais durante o período de isolamento social. Neste sentido, algumas informações poderiam ser coletadas por meio de entrevistas:

- Frequência de uso de aplicativos de comunicação;

- Mudança no perfil de consulta das novas tendências e coleções;

- Preferência de canal de comunicação com lojistas;

- Adoção de novas tecnologias de pagamento, dentre outras questões.

\section{ALTERNATIVAS PARA ANÁLISE DO CASO/ANÁLISE TEÓRICA}

O conteúdo, a criação e o uso da Web mudaram com a evolução e popularização das redes sociais. O surgimento de plataformas de mídia social, como Twitter, Instagram e Facebook, associado à expansão de tecnologias de informação avançadas têm gerado aumento na quantidade de troca de dados e mudado a forma como consumidores e empresas interagem entre si e com os outros (LIU et al., 2015; VASANTHAKUMAR et al., 2015).

À medida que as redes sociais estão mudando a forma como nos comunicamos, colaboramos, consumimos e criamos, os profissionais de marketing investigam sobre a relação entre as redes sociais, os negócios e a sociedade, identificando um fenômeno capaz de impactar e promover de forma atraente e efetiva conteúdos dotados de confiabilidade a outros usuários, o influenciador digital (CHANG et al., 2017). Liu e Suh (2017) sugerem em seus trabalhos que as funções tecnológicas fornecidas pelas redes sociais facilitam as pessoas a expressarem seu "eu autêntico", o que torna a fama online. À medida que mais pessoas comuns podem se tornar celebridades online é possível ampliar o entendimento sobre o papel das mídias sociais na promoção do self como marca no ambiente digital. 
O influenciador digital ou líder de opinião digital se alinha com o poder do conteúdo gerado pelo usuário de redes sociais sobre as empresas (WINTER e NEUBAUM, 2016). Evidências empíricas sugerem que o desempenho financeiro de uma empresa é significativamente afetado pelo conteúdo gerado pelo usuário nas redes sociais impactando diretamente no valor dos produtos no mercado. Assim, o efeito das redes sociais no desempenho depende não apenas da penetração nas redes sociais, mas da forma com que o conteúdo gerado por usuários da rede impacta no reconhecimento e na associação de marcas (SHARMA, 2016).

O foco no conteúdo gerado pelo usuário nas atividades de rede social também afetou a forma como os consumidores buscam informações sobre produtos, serviços e marca. Estudos conduzidos por Kapitan e Silvera (2016) encontraram evidências de que os consumidores internalizam uma informação quando são suficientemente persuadidos pelo conteúdo da mensagem a adotar suas afirmações como suas próprias crenças. Neste sentido, os influenciadores que compartilham informações e avaliações de produtos com usuários pares online, as chamadas "avaliações de consumidores online", podem ser um meio útil e influente para fornecer informações sobre produtos e serviços (LU et al., 2014).

Apesar de um fenômeno relativamente novo, os influenciadores digitais já foram objeto de estudo de profissionais de marketing em todo o mundo. Os influenciadores já foram avaliados sobre aspectos políticos, econômicos e sociais, e, sobretudo, no contexto de redes sociais. Estudos identificaram que o poder de persuasão sob uma rede de contatos e a influência dotada de credibilidade e confiabilidade exercida frente aos usuários pode estar personificado em pessoas comuns, em celebridades, líderes de opinião, experts em assuntos específicos, personalidades políticas e bloggers.

Seja qual o conceito adotado, os influenciadores digitais representam um novo tipo de endossante capaz de moldar atitudes do público por meio de blogs, tweets e o uso de outras redes sociais. Devido ao poder de persuasão dos influenciadores de mídia social e os benefícios da atuação desses influenciadores para as marcas é importante, mas escolher o endossante certo é crucial para a assertividade do anúncio, porque os consumidores vivem em um ambiente saturado de mídia e repleto de produtos (PRADHAN et al., 2016). Neste contexto, a escolha do influenciador deve ser feita com parcimônia por parte dos gestores de marketing, pois 
pode gerar tanto um resultado positivo quanto negativo para a imagem da marca no quesito percepções por parte do público alvo. Os influenciadores são capazes de atrair mais atenção para o produto, serviço ou marca em que aparecem quando os endossantes estão alinhados com suas próprias imagens (MCCORMICK, 2016; PRADHAN et al., 2016). Esse alinhamento pode resultar num aumento no volume de vendas e na lucratividade do produto, que continuam sendo metas importantes para os varejistas e, em última análise, a única maneira de as empresas sobreviverem (MCCORMICK, 2016).

Outro papel importante dos influenciadores digitais é o poder de promover e estimular o eWOM (boca a boca eletrônico). As descobertas mostram que o eWOM pode vincular fortemente o comportamento de compra com base na confiança e os seguidores/consumidores parecem se referir a comentários no Instagram para reduzir o risco percebido ao fazer uma compra com base em sua admiração e confiança em seus ídolos/influenciadores (DJAFAROVA e RUSHWORTH, 2017). Essa confiança pode ser justificada pela capacidade que os influenciadores têm de criar postagens autênticas e personalizadas, gerando um senso de credibilidade (BOYD, 2016).

Embora uma postagem de recomendação patrocinado seja uma espécie de revisão online do consumidor, também deve ser considerado um tipo de boca a boca eletrônico, pois possui recursos semelhantes ao eWOM: é rápido, economizável e anônimo (LU et al., 2014). Assim, usando as recomendações de um blogger/ influenciador para promover o eWOM positivo, o que, por sua vez, melhora a intenção de compra dos consumidores, é possível maximizar a influência no marketing de um produto, serviço ou marca em rede social, como o marketing de WoM (LU et al., 2014; LI e DU, 2017).

Em suma, o endosso de influenciadores de marcas é uma estratégia que tem, sem dúvida, uma grande importância. Os resultados em curto prazo podem não estar de acordo com as expectativas gerenciais, mas se gerenciados de forma eficaz, a estratégia de endosso de influenciadores pode trazer benefícios em longo prazo, principalmente na construção da marca (SHARMA, 2016). 


\section{Desfecho do caso}

Após a contratação dos influenciadores digitais, tanto o shopping quanto a agência, ainda estão analisando os dados dispostos em planilha e buscando construir indicadores para mensurar o retorno do investimento feito nesta nova modalidade de divulgação. No entanto, a partir da observação geral dos dados, foi observado um forte crescimento no número de seguidores no perfil do Instagram do Shopping Goiás Moda. No início das ações com influenciadores, em maio do ano de 2018, o perfil estava com 3.300 seguidores e um ano depois esse número saltou para 12.648 (aumento de mais de $280 \%$ ). Também foi verificado aumento no número de cliques no site e na métrica central de taxa de ocupação do shopping. Antes da ação, 2016 e 2017, o shopping estava com cerca de $60 \%$ das lojas ocupadas e, ao final da ação, esse percentual saltou para mais de $80 \%$.

Ainda será preciso identificar se o aumento da taxa de ocupação esteve relacionado com os investimentos em divulgação via influenciadores digitais e analisar mais profundamente os dados coletados formando indicadores para monitoramento dos resultados. Dessa forma, a estratégia em execução é fomentar em conjunto com uma universidade local uma pesquisa em que o foco será propor indicadores que possam ser monitorados, em especial, aquele em que o investimento no ambiente digital reflita na taxa de ocupação dentro do próprio shopping.

É esperado ainda a condução uma pesquisa que permita avaliar, de forma integrada e individual, o retorno das ações dos influenciadores em métricas como: vendas totais do shopping, venda por loja, ticket médio, fluxo de consumidores, dentre outras. Métricas que o shopping não tem acesso e estão em discussão com os lojistas para que possam ser coletadas. Foi feita uma primeira tentativa a partir da veiculação de um cupom desconto nas postagens dos influenciadores contratados para identificar se as vendas estavam relacionadas as postagens. Porém, a diretoria de marketing não conseguiu a participação da maioria dos lojistas para identificar se os consumidores conheceram o shopping, a loja, ou os produtos a partir das ações realizadas com os influenciadores digitais. 


\section{Referências}

ABRASCE. Polo de moda de Goiânia recebeu mais de 9 milhões de compradores. Associação Brasileira de Shopping Centers, 01 fevereiro 2019. Disponível em: <http://www.textilia.net/materias/ler/moda/moda-vestuario--mercado/polo_de_moda_de_goiania_recebeu_mais_de_9_milhoes_de_pessoas>. Acesso em: 08 agosto 2020.

ALMEIDA, M. I. S.; COELHO, R. L. F.; CAMILO-JUNIOR, C. G.; GODOY, R. M. F. Quem Lidera sua Opinião? Influência dos Formadores de Opinião Digitais no Engajamento. Revista de Administração Contemporânea, v. 22, n. 1, p.115-137, 2018. DOI: 10.1590/1982-7849rac2018170028.

BOYD, S. How Instagram micro-influencers are changing your mind one sponsored post at a time 2016. Disponível em: < http://www.forbes.com/sites/sboyd/2016/06/28/how-instagram-micro-influencers-arechanging-your-mind-one-sponsored-post-at-a-time/\#6132e69543c1 >. Acesso em: 30 março 2018.

CHANG, H. L.; CHOU, Y. C.; WU, D. Y.; \& WU, S. C. Will firm's marketing efforts on owned social media payoff? A quasi-experimental analysis of tourism products. Decision Support Systems, v. 107, p. 13-25, 2017. DOI: 10.1016/j.dss.2017.12.011.

COELHO, R. L. F.; DE MIRANDA, J. R.; CAMARGO FILHO, A.; FREITAG, M. S. B.; DE ALMEIDA, M. I. S. Gestão do marketing em micro e pequenas empresas. REGEPE-Revista de Empreendedorismo e Gestão de Pequenas Empresas, v. 4, n. 2, p. 219-250, 2015. DOI: 10.14211/regepe. v4i2.197.

COELHO, R. L. F.; ALMEIDA, M. I. S.; GOMES, A. C.; CAMARGO FILHO, A. O Impacto dos Influenciadores Digitais Espontâneos nas Métricas de Engajamento de uma Rede Social Virtual. In CONGRESSO LATINO AMERICANO DE VAREJO, 2017.

DANTAS, Fernando. Indústria de Moda Goiana Busca se Fortalecer no Mercado Nacional. A Redação, 22 outubro 2019. Disponível em: <https://www.aredacao.com.br/negocios/125441/industria-da-moda-goiana-busca-se-fortalecer-no-mercado-nacional>. Acesso em: 08 agosto 2020.

DJAFAROVA, E.; RUSHWORTH, C. Exploring the credibility of online celebrities' Instagram profiles in influencing the purchase decisions of young female users. Computers in Human Behavior, v. 68, p. 1-7, 2017. DOI: 10.1016/j.chb.2016.11.009.

KAPITAN, S.; SILVERA, D. H. From digital media influencers to celebrity endorsers: attributions drive endorser effectiveness. Marketing Letters, v. 27, n. 3, p. 553-567, 2016. DOI: 10.1007/s11002-015-9363-0 . LI, F.; DU, T. C. Maximizing micro-blog influence in online promotion. Expert Systems with Applications, v. 70, p. 52-66, 2017. DOI: 10.1016/j.eswa.2016.10.060.

LIU, R.; SUH, A. Self-Branding on Social Media: An Analysis of Style Bloggers on Instagram. Procedia Computer Science, v. 124, p. 12-20, 2017. DOI: 10.1016/j.procs.2017.12.124.

LIU, S.; JIANG, C.; LIN, Z.; DING, Y.; DUAN, R.; XU, Z. Identifying effective influencers based on trust for electronic word-of-mouth marketing: A domain-aware approach. Information Sciences, v. 306, p. 34-52, 2015. DOI: 10.1016/j.ins.2015.01.034

LU, L.-C.; CHANG, W.-P.; CHANG, H. H. Consumer attitudes toward blogger's sponsored recommendations and purchase intention: The effect of sponsorship type, product type, and brand awareness. Computers in Human Behavior, v. 34, p. 258-266, 2014. DOI: 10.1016/j.chb.2014.02.007. 
Do "Off" ao "On" no Mercado Atacado de Moda: o Potencial de Influenciadores Digitais

From Off to On in the Wholesale Fashion Market: the Potential of Digital Influencers

Ricardo Limongi | Ana Paula Cândida Dias | André Luiz Barbosa da Silva | Denise Santos de Oliveira |

Otávio Bandeira de Lamônica Freire

MCCORMICK, K. Celebrity endorsements: Influence of a product-endorser match on Millennials attitudes and purchase intentions. Journal of retailing and consumer services, v. 32, p. 39-45, 2016. DOI: 10.1016/j. jretconser.2016.05.012.

ORANGE CLUBE GROUP. Social Media Canvas, 05 agosto 2020. Disponível em: <https://www.spencerfield.me/smc>. Acesso em: 08 agosto 2020.

PRADHAN, D.; DURAIPANDIAN, I.; SETHI, D. Celebrity endorsement: How celebrity-brand-user personality congruence affects brand attitude and purchase intention. Journal of Marketing Communications, v. 22, n. 5, p. 456-473, 2016. DOI: 10.1080/13527266.2014.914561.

SHARMA, R. Effect of Celebrity Endorsements on Dimensions of Customer-based Brand Equity: Empirical Evidence from Indian Luxury Market. Journal of Creative Communications, v. 11, n. 3, p. 264-281, 2016. DOI: $10.1177 / 0973258616667185$.

STATISTA. Instagram influencer marketing spending worldwide from 2013 to 2020 (in million U.S. dollars), 14 dezembro 2018. Disponível em: <https://www.statista.com/statistics/950920/global-instagram-influencer-marketing-spending/>. Acesso em: 05 agosto 2020.

STATISTA. Social network user growth rate in selected Latin American countries between July 2017 and February 2018, by platform, 2020, 01 abril 2018. Disponível em: <https://www.statista.com/statistics/942943/social-network-user-growth-rate-latin-america-platform/>. Acesso em: 05 agosto de 2020.

VASANTHAKUMAR, G. U.; PRAJAKTA, B.; SHENOY, P. D.; VENUGOPAL, K. R.; PATNAIK, L. M.. PIB: Profiling Influential Blogger in Online Social Networks, A Knowledge Driven Data Mining Approach. Procedia Computer Science, v. 54, p. 362-370, 2015. DOI: 10.1016/j.procs.2015.06.042

WINTER, S.; NEUBAUM, G. Examining characteristics of opinion leaders in social media: A motivational approach. Social Media+ Society, v. 2, n. 3, p. 1-12, 2016. DOI: 10.1177/2056305116665858. 